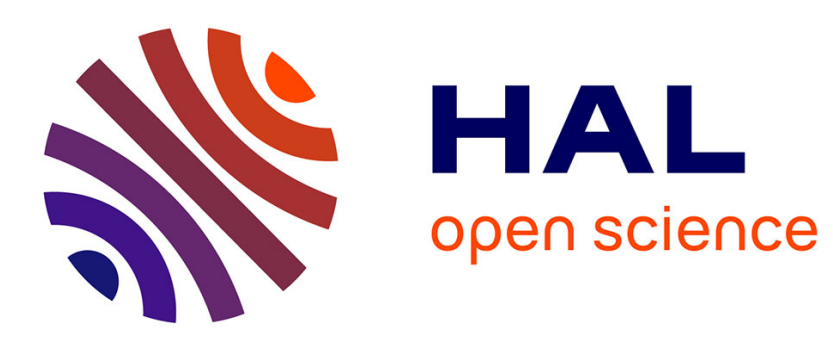

\title{
Active devices choice and design of an all cryogenic superconductor resonator oscillator
}

David Chaudy, Olivier Llopis, B Marcilhac, Y Lemaitre, Olivier D'allivy Kelly, J.-M Hode

\section{- To cite this version:}

David Chaudy, Olivier Llopis, B Marcilhac, Y Lemaitre, Olivier D'allivy Kelly, et al.. Active devices choice and design of an all cryogenic superconductor resonator oscillator. 2017 European Frequency and Time Forum \& International Frequency Control Symposium (EFTF-IFCS 2017), Jul 2017, Besançon, France. 4p. hal-01568097

\section{HAL Id: hal-01568097 \\ https://hal.science/hal-01568097}

Submitted on 24 Jul 2017

HAL is a multi-disciplinary open access archive for the deposit and dissemination of scientific research documents, whether they are published or not. The documents may come from teaching and research institutions in France or abroad, or from public or private research centers.
L'archive ouverte pluridisciplinaire HAL, est destinée au dépôt et à la diffusion de documents scientifiques de niveau recherche, publiés ou non, émanant des établissements d'enseignement et de recherche français ou étrangers, des laboratoires publics ou privés. 


\title{
Active devices choice and design of an all cryogenic superconductor resonator oscillator
}

\author{
D. Chaudy ${ }^{1,3}$, O. Llopis ${ }^{1}$ \\ ${ }^{1}$ LAAS-CNRS, Université de Toulouse, CNRS \\ 7 avenue du Colonel Roche, 31031, Toulouse, France \\ dchaudy@laas.fr
}

\author{
B. Marcilhac ${ }^{2}$, Y. Lemaitre ${ }^{2}$, O. d'Allivy Kelly ${ }^{2}$ \\ ${ }^{2}$ Unité Mixte de Physique, CNRS, Thales, Paris-Sud \\ Université Paris-Saclay, 91767, Palaiseau, France
}

\author{
J.-M. Hode ${ }^{3}$ \\ ${ }^{3}$ Thales Systèmes Aéroportés \\ 75-77 Avenue Marcel Dassault, 33700, Mérignac, France
}

\begin{abstract}
Several silicon-germanium bipolar transistors have been measured at cryogenic temperature regarding their gain and phase noise performance. The electrical model of the chosen device has been extracted. Using this model, the phase noise performance of a cryogenic superconductor oscillator has been simulated. The results are very promising, with a phase noise level of $-155 \mathrm{dBc} / \mathrm{Hz}$ at $1 \mathrm{kHz}$ offset from of a $1 \mathrm{GHz}$ carrier.
\end{abstract}

Keywords-Microwave oscillator; phase noise; SiGe transistor; nonlinear modeling; superconductors; cryogenics

\section{INTRODUCTION}

Recent research on high-temperature superconductors (HTS) has led to the development of very high Q planar resonators. Associated with a well-chosen amplifier, those resonators would make a very efficient low phase noise oscillator. This device could outperform the performance of the best quartz referenced oscillators in the low microwave range (near $1 \mathrm{GHz}$ ). Indeed, high quality factors of 250000 have been demonstrated around $1 \mathrm{GHz}[1,2,3]$ with those HTS planar resonators. However, no oscillator with HTS resonators has yet included a low-temperature RF amplifier.

In this paper, the selection and modeling of transistors that can be used to design a low-temperature low phase noise amplifier is described. Then, a fully integrated $1 \mathrm{GHz}$ oscillator working at 60 Kelvin is simulated. The goal is to outperform by $10 \mathrm{~dB}$ at least the best commercially available $1 \mathrm{GHz}$ sources, which generally feature a phase noise level in the range of $-140 \mathrm{dBc} / \mathrm{Hz}$ at $1 \mathrm{kHz}$ offset from $1 \mathrm{GHz}$ carrier.

\section{DEVICES SELECTION}

Bipolar SiGe-heterojunction transistors are known for their low 1/f noise properties at ambient temperature. Also, contrarily to all-silicon devices, they keep their current and gain performance at low temperature $[4,5]$. For this reason, four $\mathrm{SiGe}$ transistors have been chosen and characterized both at $300 \mathrm{~K}$ and at cryogenic temperature. A first test campaign has been conducted at $80 \mathrm{~K}$, using liquid nitrogen, to simplify the experimental procedure. A second campaign at $60 \mathrm{~K}$ is scheduled to fully validate the model of the selected transistor.
Indeed, the oscillator operation temperature will be $60 \mathrm{~K}$, which ensures an optimized performance of the resonator. All transistors have been measured in common emitter topologies, between two $50 \Omega$ isolators and submitted to a $1 \mathrm{GHz}$ signal. The selection has been based on the combination of two RF parameters: the residual phase noise at the 1-dB compression point and the $50 \Omega$ gain $\left(\mathrm{S}_{21}\right)$ at $1 \mathrm{GHz}$.

All measurements have been conducted on a phase noise test bench (Fig. 1) which has been specially optimized for $1 \mathrm{GHz}$ operation. It is based on an ultra-low phase noise $1 \mathrm{GHz}$ source (a multiplied OCXO), uses two phase detectors to benefit from the correlation approach and a search for an optimized rejection of the source AM noise [6] (fine tuning of the quadrature condition).

Specific transistor test fixtures have been used to perform precise RF measurements at low temperature. Indeed, a TRL calibration set for $\mathrm{S}$ parameters measurements has been designed with the same test fixtures. Gain $\left(\mathrm{S}_{21}\right)$ and phase noise results are summarized in Table 1 and 2, for respectively $300 \mathrm{~K}$ and $80 \mathrm{~K}$ performance.

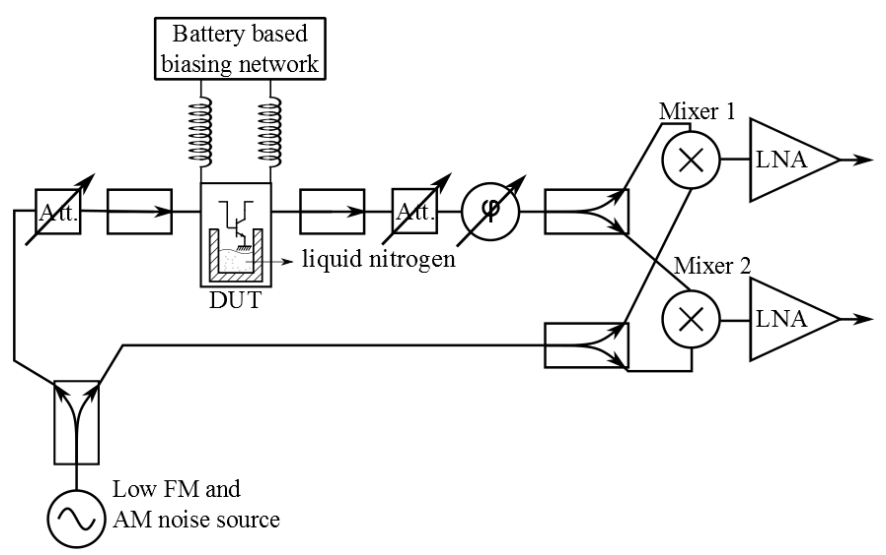

Fig. 1. Test bench for the residual phase noise measurement of a device in liquid nitrogen. 
TABLE I. PHASE NOISE AND RF GAIN AT AMBIENT TEMPERATURE.

\begin{tabular}{|l|l|l|l|l|}
\hline $\begin{array}{c}\text { Phase noise }\left(\mathrm{dBrad}^{2} / \mathrm{Hz}\right) \\
\text { and } \mathrm{S}_{\mathbf{2 1}} \text { at } \mathbf{1 ~ G H z} \text { and 300K }\end{array}$ & $\mathbf{1 0 0} \mathbf{H z}$ & $\mathbf{1} \mathbf{k H z}$ & $\mathbf{1 0 0} \mathbf{k H z}$ & Gain $(\mathrm{dB})$ \\
\hline TR-1 & -149 & -157 & -166 & 21.5 \\
\hline TR-2 & -156 & -164 & -169 & 20.0 \\
\hline TR-3 & -136 & -157 & -164 & 21.3 \\
\hline TR-4 & -163 & -170 & -175 & 14.7 \\
\hline
\end{tabular}

TABLE II. PHASE NOISE AND RF GAIN AT LOW TEMPERATURE.

\begin{tabular}{|l|l|l|l|l|}
\hline $\begin{array}{c}\text { Phase noise }(\mathrm{dBrad} / \mathbf{H z}) \\
\text { and } \mathbf{S}_{\mathbf{2}} \text { at } \mathbf{1 ~ G H z ~ a n d ~ 8 0 ~ K}\end{array}$ & $\mathbf{1 0 0} \mathbf{H z}$ & $\mathbf{1} \mathbf{k H z}$ & $\mathbf{1 0 0} \mathbf{k H z}$ & Gain (dB) \\
\hline TR-1 & -130 & -155 & -162 & 19.0 \\
\hline TR-2 & -155 & -162 & -169 & 21.4 \\
\hline TR-3 & -134 & -144 & -158 & 24.4 \\
\hline TR-4 & -147 & -156 & -169 & 15.6 \\
\hline
\end{tabular}

TR-2 transistor has been chosen among the tested devices. As illustrated in Fig. 2, this transistor features a good residual phase noise level and almost the same performance at ambient and cryogenic temperature.

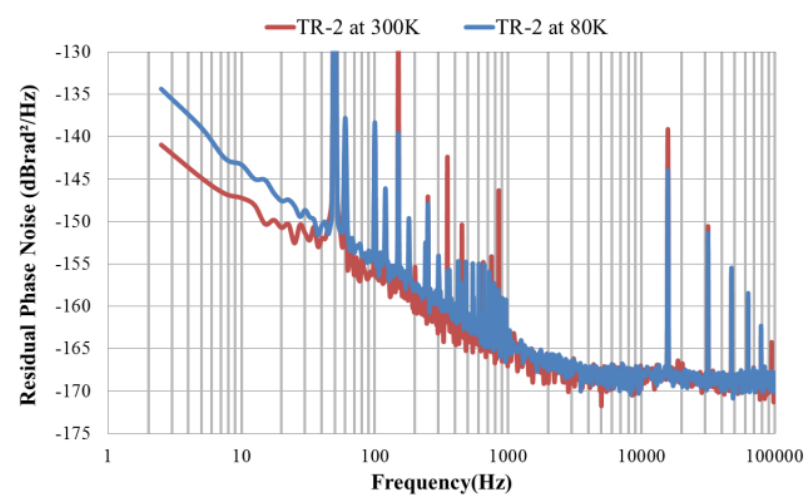

Fig. 2. Measured of TR-2 residual phase noise at $1 \mathrm{GHz}$. Low and ambient temperature measurements with $\mathrm{I}_{\mathrm{C}}=30 \mathrm{~mA}$ and $\mathrm{V}_{\mathrm{CE}}=2 \mathrm{~V}$.

By using the same test bench, a second investigation has been performed. This time, two silicon phase tuning diodes (varactor diodes) have been tested. Both were measured at ambient and low temperature $(60 \mathrm{~K})$, and their electrical behavior was unchanged, as illustrated Fig 3. Used in series connected between two $50 \Omega$ loads, these diodes do not add significant phase noise to a $1 \mathrm{GHz} \mathrm{RF}$ loop. We tried to measure this phase noise contribution, both at ambient temperature and $80 \mathrm{~K}$, both at low RF input power $(0 \mathrm{dBm})$ or high RF input power $(10 \mathrm{dBm})$, but it was in each case lower than our phase noise measurement bench capabilities, i.e. $-171 \mathrm{dBrad}^{2} / \mathrm{Hz}$ at $1 \mathrm{kHz}$ offset.

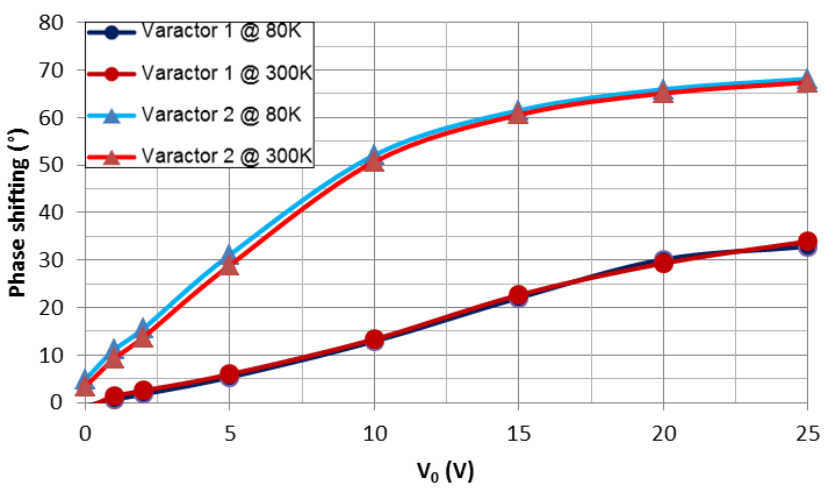

Fig. 3. Phase variation at $1 \mathrm{GHz}$ induced by two in-series connected varactor diodes at low temperature and ambient temperature.

\section{LOW-TEMPERATURE NON-LINEAR MODEL}

To perform the oscillator design, the physical and electrical characteristics of the active device must be known. Therefore DC, dynamic, low-frequency noise and phase noise measurements have been performed at $80 \mathrm{~K}$. Thanks to those measurements the transistor non-linear model (Gummel-Poon model) has been extracted using Keysight ADS software. Moreover several TR-2 transistors have been tested to validate this model.

This model allows us to fit simulations and measurements for DC-characteristics and S parameters (cf Fig. 4 to Fig. 7 for $\mathrm{I}(\mathrm{V}), \mathrm{S}$-parameters and output power versus input power). However, concerning the noise, the problem is more complex: an accurate model of the transistor intrinsic noise sources need to be used. Several existing methods and models have already proven their accuracy for SiGe HBT phase noise modeling at ambient temperature. The one we have used is described in the reference [7]. Fig. 8 shows that the implemented model fit the measured residual phase noise.

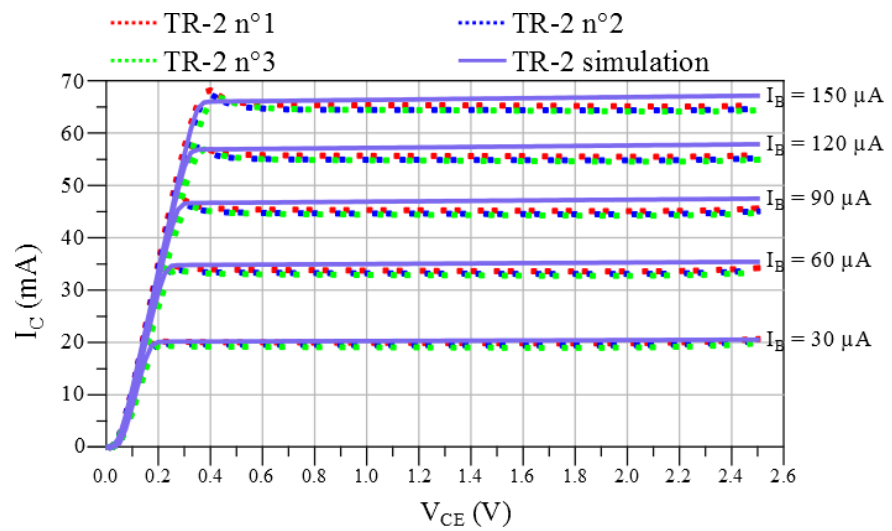

Fig. 4. Simulated and measured DC current-voltage curves at $80 \mathrm{~K}$ for 3 different TR-2 transistors. 


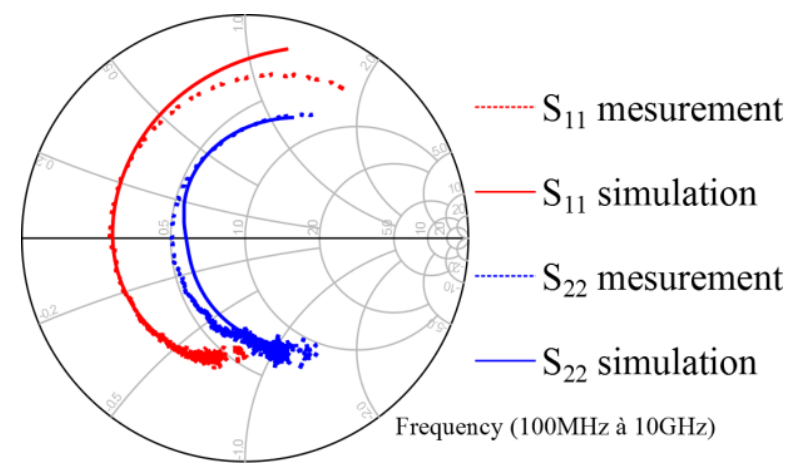

Fig. 5. Simulated and measured $S_{11}$ and $S_{22}$ parameters curves at $80 \mathrm{~K}$ for a TR-2 transistor.

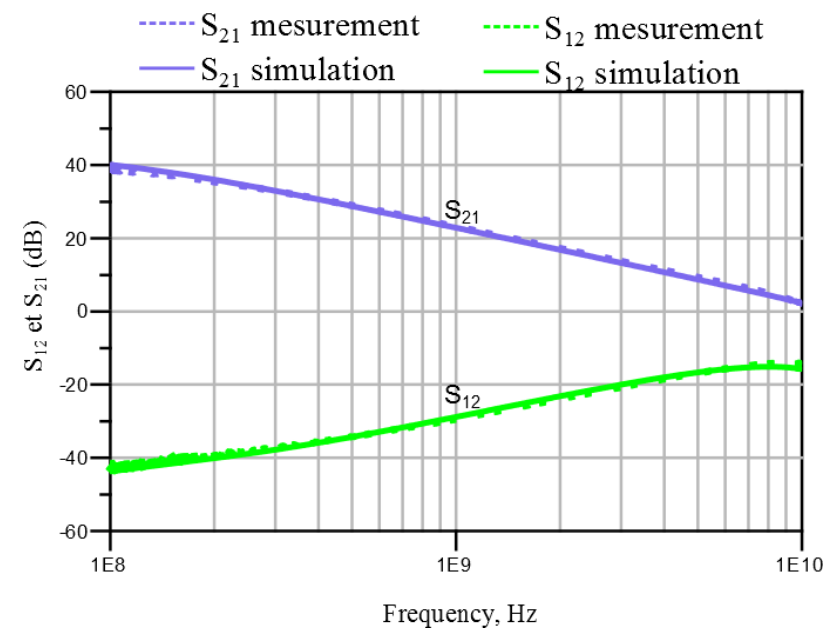

Fig. 6. Simulated and measured $S_{21}$ and $S_{12}$ parameters curves at $80 \mathrm{~K}$ for a TR-2 transistor.

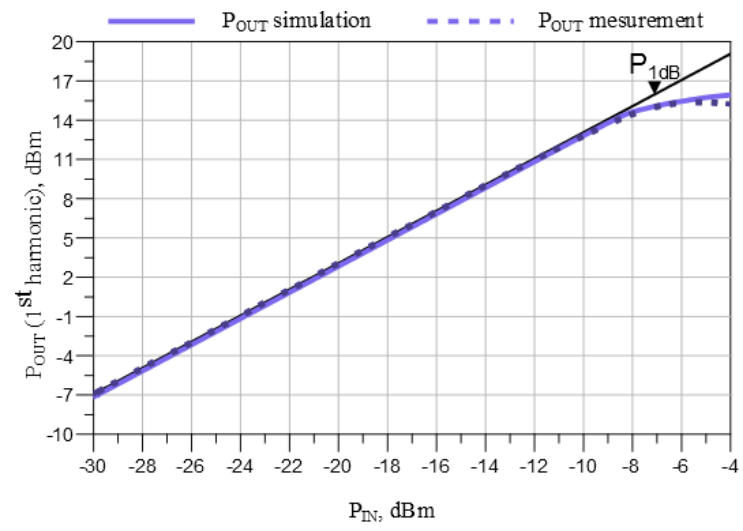

Fig. 7. Simulated and measured power caracteristics at $80 \mathrm{~K}$ for a TR-2 transistor.

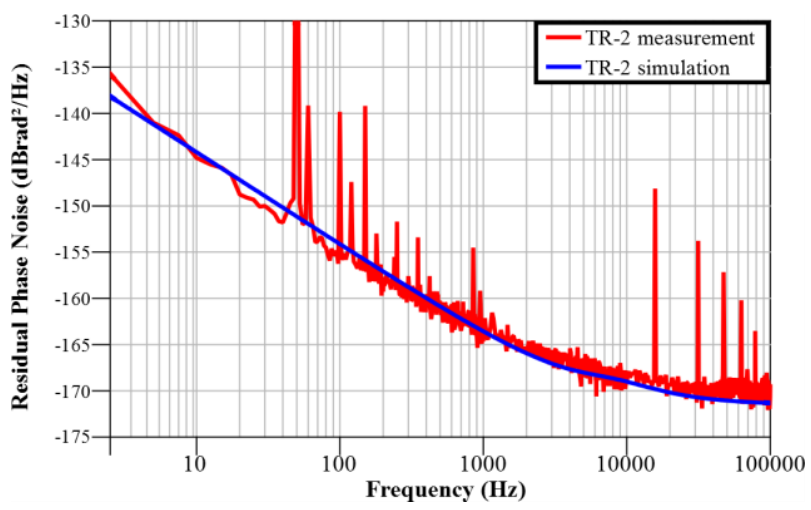

Fig. 8. Simulated and measured TR-2 residual phase noise at $1 \mathrm{GHz}$. $\mathrm{I}_{\mathrm{C}}=30 \mathrm{~mA}, \mathrm{~V}_{\mathrm{CE}}=2 \mathrm{~V}, \mathrm{~T}=80 \mathrm{~K}$.

\section{OSCILLATOR SIMULATION}

An oscillator has been designed using TR-2 device and a planar HTS resonator model. The oscillation loop is presented in Fig. 9. The active part of the oscillator is realized on an alumina substrate and link by wire bounding to the HTSresonator. Apart from the low phase noise amplifier, the coupler, the varactor and the lines that adjust the $2 \pi$ phase loop are also realized on the alumina substrate. To stabilize, match the amplifier and optimize its residual phase noise, several resistances and capacitors were added (Fig. 10). Then the all integrated oscillator is implemented on the top of the cryocooler's cold finger.

The simulated phase noise is depicted in Fig. 11 and features $-155 \mathrm{dBc} / \mathrm{Hz}$ at $1 \mathrm{kHz}$ offset. This phase noise level has been obtained with an HTS resonator featuring an unloaded Q of 290000 at $1 \mathrm{GHz}$ and a loaded Q of 110000 .

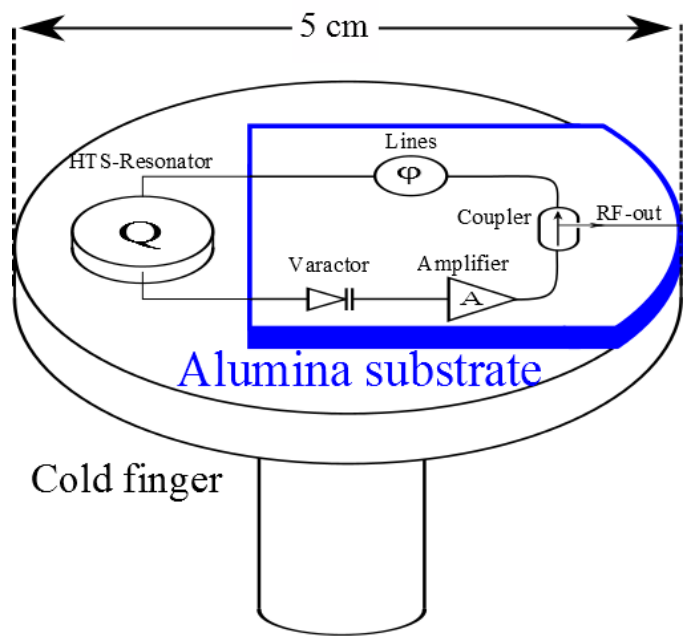

Fig. 9. Picture of the oscillator topology and of its implementation on the cold finger of the cryostat. 


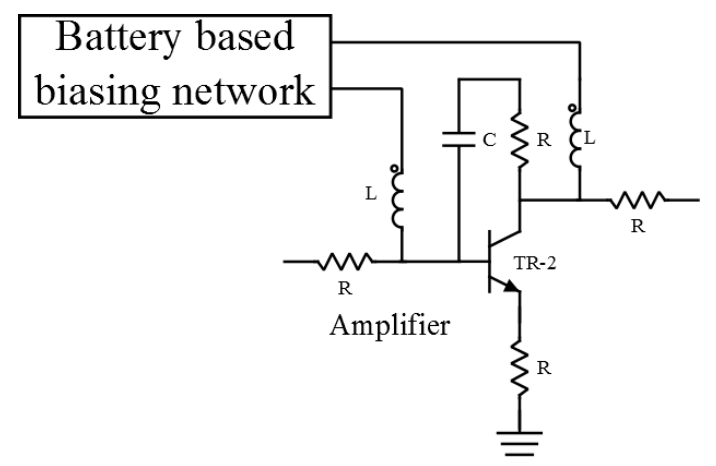

Fig. 10. Amplifier based on TR-2 transistor.

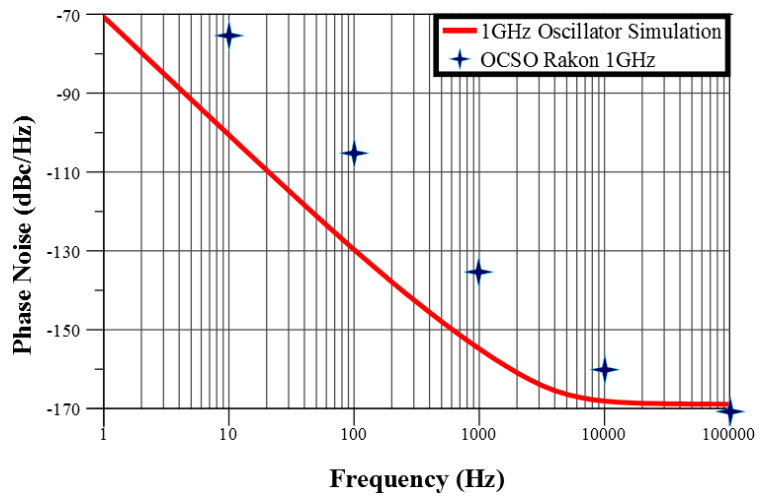

Fig. 11. Simulated $1 \mathrm{GHz}$ oscillator phase noise with TR-2 transistor model and HTS resonator $\left(\mathrm{Q}_{\mathrm{L}}=110000\right)$.

\section{CONCLUSION}

Characterization of $\mathrm{SiGe}$ devices at low temperature for oscillator design has been presented. A nonlinear model extraction has been performed on one of these devices at $80 \mathrm{~K}$. The model is able to predict the phase noise performance in amplifier configuration. A superconductor cavity oscillator has been designed using this model and the simulation shows very promising phase noise results. This oscillator will be soon realized on an alumina substrate.

\section{REFERENCES}

[1] J. Kermorvant, PhD thesis (in french), Ecole Polytechnique, 2010.

[2] M. Reppel and J. C. Mage, "Superconducting microstrip bandpass filter on $\mathrm{LaAlO}_{3}$ with high out-of-band rejection," in IEEE Microwave and Guided Wave Letters, vol. 10, no. 5, pp. 180-182, May 2000.

[3] J.-C. Mage, B. Marcilhac, M. Poulain, Y. Lemaitre, J. Kermorvant, J.-M. Lesage, " Low noise oscillator based on 2D superconducting resonator » 2011 EFTF and IEEE-IFCS conference.

[4] S. Gribaldo, PhD thesis (in french), Toulouse University, 2008.

[5] S. Weinreb, J. C. Bardin and H. Mani, "Design of Cryogenic SiGe LowNoise Amplifiers," in IEEE Transactions on Microwave Theory and Techniques, vol. 55, no. 11, pp. 2306-2312, Nov. 2007.

[6] G. Cibiel, M. Regis, E. Tournier, O. Llopis, « AM noise impact on low level phase noise measurements » IEEE trans. on Ultrasonics Ferroelect. and Freq. Control, vol. 49, n ${ }^{\circ}$ 6, Juin 2002, pp. 784-788.

[7] S. Gribaldo, L. Bary, O. Llopis, «SiGe HBT nonlinear phase noise modeling - X band amplifier design », Proc. of the EuMA, 2008, v. 4, pp. $177-182$. 